\title{
Schwannoma of the Colon
}

\author{
Ronaldo Nonose $^{a} \quad$ Alberto Youssef Lahan ${ }^{b}$ \\ Juliana Santos Valencianoc Carlos Augusto Real Martinez ${ }^{d}$ \\ ${ }^{a}$ Assistant Professor in General Surgery, Medical Course, São Francisco University, \\ Bragança Paulista, bAttending Physician, Baeta Neves Hospital, São Bernardo do \\ Campo, São Paulo, 'Undergraduate Student, Medical Course, São Francisco \\ University, Bragança Paulista, dAdjunct Professor of the Postgraduate Health \\ Sciences Program of São Francisco University and Head of the General Surgery \\ Service of São Francisco University Hospital, Bragança Paulista, Brazil
}

\section{Key Words}

Schwannoma $\cdot$ Neurilemoma $\cdot$ Colon · Colon neoplasms · Immunohistochemistry · S-100 protein $\cdot \mathrm{Ki}-67$ antigen

\begin{abstract}
Schwannomas are neoplasms originating from Schwann cells, which are the cells forming nerve sheaths. These neoplasms generally involve peripheral nerves. They rarely affect the gastrointestinal tract and primary colon involvement is extremely rare. The objective of the present paper was to present a case of primary schwannoma of the sigmoid colon, unassociated with von Recklinghausen disease, that was histopathologically confirmed by means of an immunohistochemical panel. The patient was a 71-year-old woman who had had rectal bleeding when evacuating, with pain and tenesmus, for 4 months. She underwent colonoscopy, which identified a raised submucous lesion of $2.8 \mathrm{~cm}$ in diameter, located in the sigmoid colon, $30 \mathrm{~cm}$ from the anal margin. During examination, loop polypectomy with lesion excision was performed. Histopathological evaluation showed that this was a tumor of stromal origin. Its resection margins were compromised by neoplasia, and colon resection by means of videolaparoscopy was indicated. Conventional histopathological examination using the hematoxylin-eosin technique suggested that the neoplasm was of mesenchymal origin. An immunohistochemical panel was run for etiological confirmation, using anti-CD34 antibodies, desmin, cytokeratins (AE1/AE3), cKit, chromogranin and S-100 protein. The panel showed intense immunoexpression of S-100 protein. Investigation of the proliferative activity rate using Ki-67 antibodies showed that there was a low rate of mitotic activity, thus confirming the diagnosis of primary benign schwannoma of the colon. The patient's postoperative evolution was uneventful and she remains in good health, without signs of tumor recurrence, 15 months after surgical excision.
\end{abstract}




\section{Introduction}

Schwannomas are rarely described neoplasms originating from the Schwann sheath. They develop most frequently in peripheral nerves in the limbs, head and neck. Visceral involvement is uncommon [1]. It has been estimated that schwannomas represent only 2$6 \%$ of all stromal tumors of the digestive tract. These most frequently affect the stomach and small intestine $[1,2]$.

There are many synonyms for neurogenic tumors of the digestive tract, namely schwannoma, neurinoma, neurogenic fibroma, neurofibroma, neurilemoma and plexiform neurofibromatosis. These different names are used with the intent of relating them to the structure from which they originate. Because of the differences in the nomenclature used, it remains difficult to precisely establish the correct prevalence of primary tumors of the neural sheath $[1,3]$. Although there is some controversy regarding the cell origin, classification and correct naming of gastrointestinal tract schwannomas, there is evidence showing that these neoplasms originate from Schwann cells in the neurons of the myenteric plexus $[4,5]$.

Primary schwannomas of the colon and rectum, unassociated with systemic neurofibromatosis (von Recklinghausen disease), are extremely rare. It is estimated that there are around 50 published cases [6-9]. The objective of the present paper was to present a case of benign primary schwannoma of the sigmoid colon, unassociated with von Recklinghausen disease, that was histopathologically confirmed by means of an immunohistochemical panel and was successfully treated by means of videolaparoscopic colectomy.

\section{Case Report}

The patient was a 71-year-old woman with complaints of tenesmus and hematochezia for 4 months, associated with weight loss of $4 \mathrm{~kg}$. Nine months earlier she had undergone colonoscopy and a sessile polypoid lesion in the sigmoid colon, $0.5 \mathrm{~cm}$ in diameter, had been removed. Histopathological evaluation at that time had led to the diagnosis of a hyperplastic polyp in the colon. Even with endoscopic removal of the polyp, she did not present any improvement in symptoms. She continued to present successive episodes of fresh bleeding when evacuating, and this was associated with rectal pain and tenesmus. With these complaints, she sought the Coloproctology Service of São Francisco University, where she underwent another colonoscopy. This second examination found a reddish polypoid lesion of approximately $3 \mathrm{~cm}$ in diameter, located in the sigmoid colon $35 \mathrm{~cm}$ from the anal margin. The surface of the mucosa covering the lesion was ulcerated and it presented slight local bleeding when in contact with the apparatus. It was removed by means of loop polypectomy. Conventional histopathological examination using the hematoxylin-eosin technique showed that spindle cells were present, arranged in bundles, with dense distribution of nucleus forming palisades in dense fibrillar stroma (fig. 1).

With the diagnostic suspicion of a tumor of mesenchymal origin, an immunohistochemical panel was performed for anti-CD34 antibodies, desmin, cytokeratins (AE1/AE3), cKit, chromogranin and S-100 protein. Intense immunoexpression of S-100 protein was found (fig. 2 ), while the other antibodies presented negative results (table 1). With the aim of evaluating tumor growth potential, an immunohistochemical investigation was performed on the Ki-67 cell proliferation factor. Positive results were found in fewer than $5 \%$ of the fields analyzed (one mitosis in every ten fields at high magnification), thus suggesting that the neoplasm had a low mitotic rate (fig. 3 ). The results from the histopathological and immunohistochemical examinations allowed the diagnostic conclusion that this was a case of benign schwannoma of the sigmoid colon with a histological pattern of Antoni A type, with a low degree of cell proliferation (fig. 1). The surgical margins of the lesion removed were compromised with neoplasia, and therefore it was decided to perform video-assisted colectomy.

The patient's postoperative evolution was uneventful and she was discharged from hospital on the fourth postoperative day. Histopathological examination on the resected colon confirmed that it 
presented a residual neoplastic lesion with the same characteristics as presented by the polyp that was removed during colonoscopy. The resected margins obtained after surgical resection were free from involvement and there was no neoplastic involvement in any of the 21 lymph nodes examined. At present, the patient is well, without any recurrence of symptom, and a control colonoscopy examination performed 15 months after the colectomy showed normal results.

\section{Discussion}

Tumors originating from autonomous nerves of the digestive tract form a distinct but rare subcategory of stromal gastrointestinal tumors, accounting for approximately $1 \%$ of all neoplasms affecting the digestive tract [10]. Schwannomas are neoplasms of ectodermic origin that are usually benign. They have slow growth and present the possibility of malignant degeneration when not removed $[1,11]$. They affect men and women with equal frequency and can appear at any age, but most commonly after the sixth decade of life [12]. When they appear in the digestive tract, the stomach and the small intestine are the segments most frequently involved, accounting for 83 and $12 \%$ of such cases, respectively [3]. Schwannomas located in the colon and rectum that are unrelated to von Recklinghausen disease are extremely rare. These neurogenic neoplasms of the digestive tract usually present indolent growth. Although they usually evolve asymptomatically, they may in some cases, as in our patient, present bleeding, rectal pain and tenesmus. It is important to highlight that unspecific rectal pain is often confused with the pain of idiopathic proctalgia fugax, which may cause delay in diagnosing the condition.

Macroscopically, schwannomas are well-delimited, lobulated tumors that may, in larger cases, present a cystic pattern. From a microscopic point of view, schwannomas are encapsulated neoplasms and two histological growth patterns have been described: Antoni A and Antoni B. In Antoni A type there is dense growth of fusiform cells, compactly arranged in palisades to form Verocay bodies. In Antoni B, the fusiform cells are more loosely distributed with rounded or elongated nuclei, with a greater quantity of myxoid stroma and xanthomatous histiocytes $[4,12]$. Typical Schwann cells covering a basal membrane are not generally identified. These findings also include undifferentiated mesenchymal cells, smooth muscle cells, cells with neural characteristics and cells with mixed differentiation of neural/muscular type [5]. Regarding our patient, the result from the histological examination using the hematoxylin-eosin technique suggested a diagnosis of schwannoma of the sigmoid colon with a cell pattern classified as Antoni A.

Before immunohistochemistry techniques came into routine use, schwannomas were wrongly diagnosed as smooth muscle neoplasms such as leiomyomas and leiomyosarcomas [13]. The use of immunohistochemical panels plays a fundamental role in diagnosing schwannomas and in ruling out other neoplasms of mesenchymal origin. Authors believed that positive immunostaining for S-100 protein and Leu7 antigen indicated a neoplasm originating from Schwann cells [14]. Strongly positive immunoexpression of S-100 protein and low affinity for CD34, cytokeratins, smooth muscle actin and desmin confirm the possibility of schwannoma in practice. The present case was within these criteria: results identical to these were found from running the immunohistochemical panel that is most commonly proposed.

The exact biological behavior of schwannomas is still not fully clear, since only a small number of cases have been published. Consequently, determination of malignity becomes a difficult challenge that cannot always be resolved using conventional histopathological techniques. Many parameters have been studied in relation to tumor behavior and, so far, 
no single parameter alone allows safe prediction of the degree of malignity. A mitotic activity rate of more than five mitoses per field at high magnification and tumor size greater than $5 \mathrm{~cm}$ tend to be associated with a high risk of metastasis or recurrence. We evaluated the number of mitoses by means of the immunohistochemical technique using Ki-67 antibodies and found a low rate of cell division, suggesting that this was a low-grade schwannoma. The low mitosis rate, the absence of atypical mitosis figures and the absence of nuclear hyperpigmentation, especially in the necrotic areas found, were also useful for characterizing the benign nature of the lesion.

Although schwannomas are considered to be benign tumors, their high recurrence risk must not be ignored [11]. In a study on 303 benign schwannoma cases unrelated to von Recklinghausen disease, Das Gupta and Brasfield found that $2 \%$ of the tumors evolved with distant metastases [14]. This evidence suggests that, despite the skepticism regarding the possibility of malignant transformation of schwannomas initially considered benign, this possibility does exist and must not be ignored. The most aggressive phenotype relates to the size of the tumor and its proliferative activity rate, and this gives rise to greater recurrence, metastases and lower overall survival rates.

The best therapeutic option is complete surgical removal with margins free from neoplastic involvement $[1,5]$. Since the risk of malignant transformation is small, broad lymph node resections are not recommended [5]. For tumors with more aggressive behavior, the same surgical criteria should be used, but greater rigor in postoperative follow-up is recommended. The surgical approach depends on the size and location of the tumor and on its histopathological pattern. Minimally invasive surgery using videolaparoscopic access, such as in the present case, may be indicated for tumors located in the proximal colon and rectum. For tumors in the distal rectum, transanal endoscopic resection can be used $[1,15]$. The use of radiotherapy or adjuvant chemotherapy still presents conflicting results and is not recommended for routine use.

In conclusion, schwannomas of the colon and rectum are tumors that are rarely detected and for which the use of an immunohistochemical panel is important to achieve a definitive histopathological diagnosis. Radical surgical removal is the preferred treatment because it allows improvement of overall survival and disease-free survival rates.

Table 1. Immunohistochemical panel used

\begin{tabular}{lll}
\hline Antibody & Cell origin & Result \\
\hline CD34 & blood vessels & negative \\
Desmin & muscle tissue & negative \\
Cytokeratins AE1 and AE3 & epithelial colon cells & negative \\
cKit & stromal tumor & negative \\
Chromogranin & neuroendrocrine tissue & negative \\
S-100 protein & Schwann sheath & positive \\
Ki-67 & cell proliferation factor & positive $<5 \%$ \\
\hline
\end{tabular}




\begin{tabular}{r|l|l|l} 
Case Reports $/$ h & $\begin{array}{l}\text { Case Rep Gastroenterol 2009;3:293-299 } \\
\text { D01: 10.1159/000237736 }\end{array}$ & Published online: September 22, 2009 & $\begin{array}{l}\text { O 2009 S. Karger AG, Basel } \\
\text { ISSN 1662-0631 } \\
\text { www.karger.com/crg }\end{array}$ \\
\hline
\end{tabular}

Fig. 1. Schwannoma of the sigmoid colon with histological pattern of Antoni A type (hematoxylin-eosin, 100x).

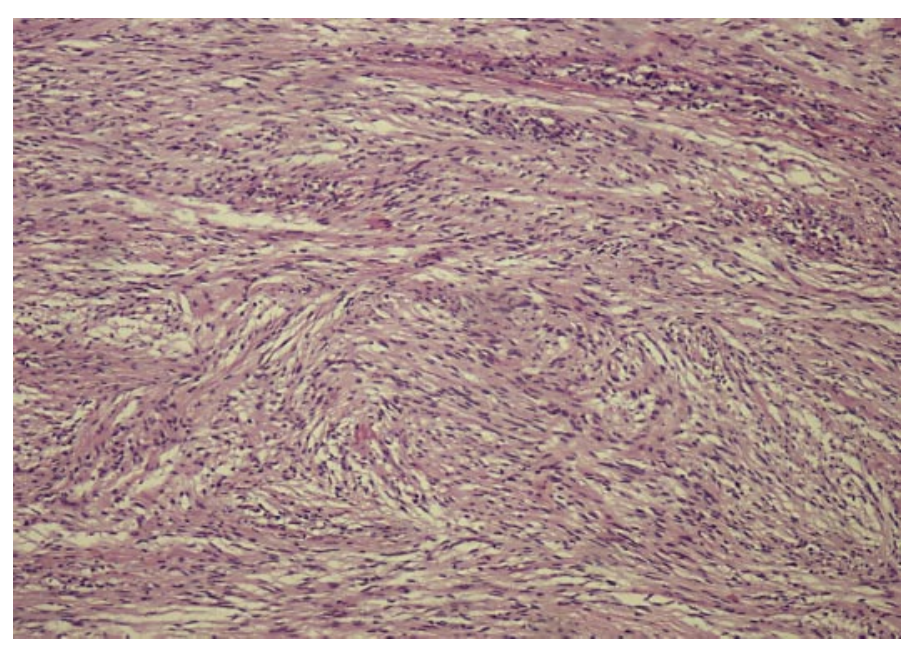

Fig. 2. Strongly positive immunoexpression of S-100 protein (immunohistochemistry, 100×).

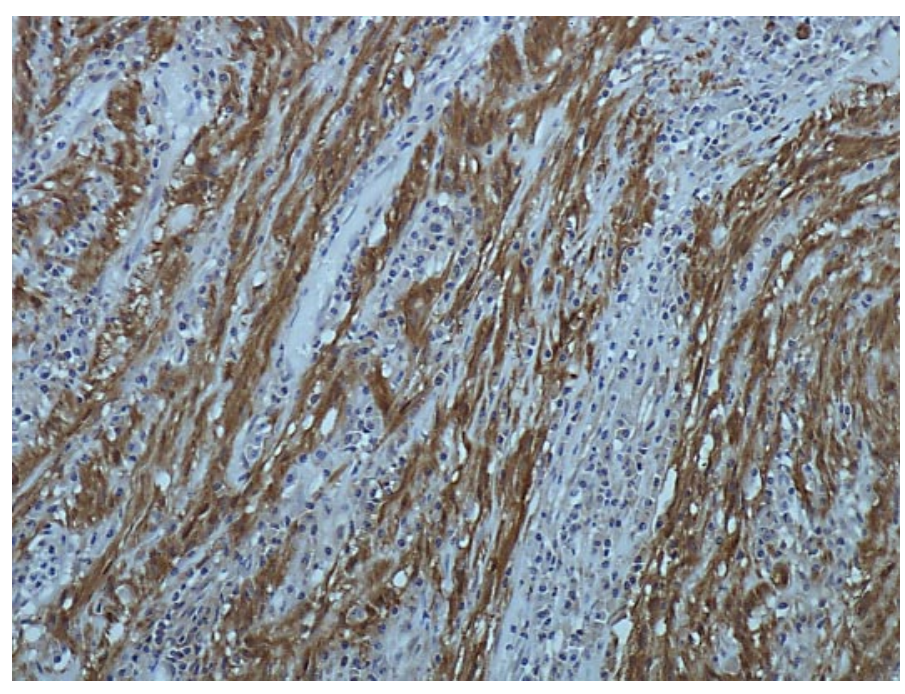




\begin{tabular}{r|l|l|l} 
Case Reports $h$ & $\begin{array}{l}\text { Case Rep Gastroenterol 2009;3:293-299 } \\
\text { Dol: } 10.1159 / 000237736\end{array}$ & Published online: September 22, 2009 & $\begin{array}{l}\text { O 2009 S. Karger AG, Basel } \\
\text { ISSN 1662-0631 } \\
\text { www.karger.com/crg }\end{array}$ \\
& & & \\
\hline
\end{tabular}

Fig. 3. Positive immunoexpression of the Ki-67 nuclear proliferation factor in fewer than $5 \%$ of the fields studied (immunohistochemistry, 100x).

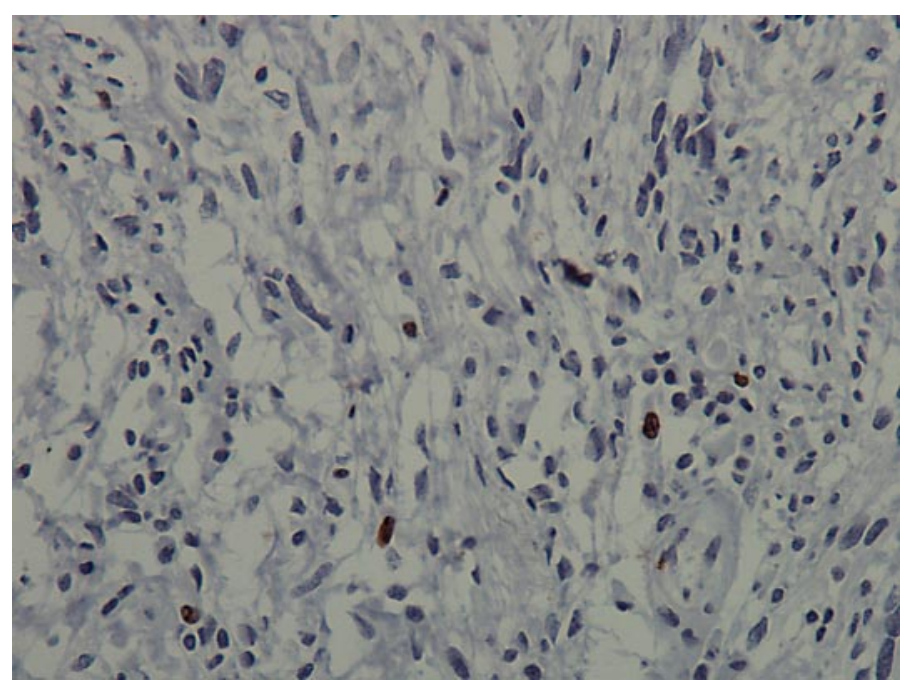




\section{References}

1 Fotiadis CI, Kouerinis IA, Papandreou I, Zografos GC, Agapitos G: Sigmoid schwannoma: a rare case. World J Gastroenterol 2005;11:5079-5081.

2 Daimaru Y, Kido H, Hashimoto H, Enjoji M: Benign schwannoma of the gastrointestinal tract: a clinicopathologic immunohistochemical study. Hum Pathol 1988;19:257-264.

-3 Sugimura H, Tamura S, Yamada H, Kusumoto S, Watanabe K, Hayashi T, Sumiyoshi A: Benign nerve sheath tumor of the sigmoid colon. Clin Imaging 1993;17:64-66.

4 Miettinen M, Shekitka KM, Sobin LH: Schwannomas in the colon and rectum. A clinicopathologic and immunohistochemical study of 20 cases. Am J Surg Pathol 2001;25:846-855.

5 Maciejewski A, Lange D, Wloch J: Case report of schwannoma of the rectum clinical and pathological contribution. Med Sci Monit 2000;6:779-782.

6 Sabchareon V, Bacon HE, Gennaro AR: Neurilemoma of the rectum and perirectal area: report of a case. Dis Colon Rectum 1968;11:356-358.

7 Abel ME, Nehme Kingsley AE, Abcarian H, Arlenga P, Barron SS: Anorectal neurilemomas. Dis Colon Rectum 1985;28:960-961.

8 Skopetitou AS, Mylonakis EP, Charchanti AV, Kappas AM: Cellular neurilemoma (schwannoma) of the descending colon mimicking carcinoma. Report of a case. Dis Colon Rectum 1998;41:1193-1196.

9 Genna M, Leopardi F, Fambri P, Pastorino A: Neurogenic tumors of the ano-rectal region. Ann Ital Chir 1997;68:351-353.

10 Mulchandani MH, Chattopadhyay D, Obafunwa JO, Joypaul VB: Gastrointestinal autonomic nerve tumours - report of a case and review of literature. World J Surg Oncol 2005;3:46-52.

11 Lauwers GY, Erlandson RA, Casper ES, Brennan MF, Woodroff JM: Gastrointestinal autonomic nerve tumours. A clinicopathological, immunohistochemical and ultrastructural study of 12 cases. Am J Surg Pathol 1993; 17:887-897.

12 Miettinen M, Sarlomo-Rikala M, Lasota J: Gastrointestinal stromal tumours. Ann Chir Gynaecol 1998;87:278-281.

13 Arai T, Sugimura H, Suzuki M, et al: Benign schwannoma of the esophagus: Report of two cases with immunohistochemical and ultrastructural studies. Pathol Int 1994;44:460-465.

14 Das Gupta TK, Brasfield RD: Tumors of peripheral nerve origin: benign and malignant solitary schwannomas. CA Cancer J Clin 1970;20:228-233.

15 Langer C, Markus P, Liersch T, Fuzesi L, Becker H: Ultracision or high frequency knife in transanal and microsurgery TEM; advantages of a new procedure. Surg Endosc 2001;15:513-517.

Work was carried out within the Postgraduate Health Sciences Program of São Francisco University, Bragança Paulista, Brazil. 